\title{
Technology in Support of Developing Speaking Skills in ESP Courses
}

\begin{abstract}
Nowadays, when face-to-face human interactions are restricted due to the COVID-19 pandemic, students have fewer opportunities to put their oral communicative abilities to the test. Under these circumstances, technology becomes an ally of both teachers and learners. While synchronous tools enable students to communicate with one another in real time, asynchronous tools allow them, among others, to record their utterances for review and self-evaluation. This paper aims to indicate which technological solutions could help teachers increase learners' oral production in the ESP classroom (with particular emphasis on Medical and Business English) and which ones could help students improve their speaking skills independently.

Keywords: technology, speaking, oral communication, speaking skills, ESP
\end{abstract}

\section{Role of speaking in ESP education}

Speaking is frequently regarded as the most challenging skill to develop in the foreign language classroom. This also applies to English for Specific Purposes (ESP) instruction, which aims to prepare students to master the language used in various professional and workplace settings to accomplish specific purposes (Hutchinson \& Waters, 1987).

ESP courses are primarily designed for learners who have to carry out specific communicative tasks prescribed by their academic or workplace contexts. The tasks may include conference presentations and discussing research results for academic purposes, medical history taking or giving a nursing handover for medical purposes, reporting ideas and designs for engineering purposes, or negotiating with suppliers for business purposes. This complexity of ESP content is observed by Orr (2001, p. 207), who defines specialist language learners as those who require special skills "to carry out highly specialised tasks for which general English may not prove sufficient". They commonly seek to develop their linguistic compe-

Agnieszka Dzięcioł-Pędich, Studium Praktycznej Nauki Języków Obcych, Uniwersytet w Białymstoku, ul. Świerkowa 20B, 15-328 Białystok, Phone: 0048857457085, adzieciol-pedich@uwb.edu.pl, https:// orcid.org/0000-0002-2292-4111

AgnieszkaDudzik,Studium JęzykówObcych,UniwersytetMedycznywBiałymstoku,ul.JanaKilińskiego1, 15-089 Białystok, agnieszka.dudzik@umb.edu.pl, https://orcid.org/0000-0003-0908-0214 
tence in English in order to be able to communicate professional information and to perform job-related tasks.

Significantly, in ESP programmes it is needs analysis that guides curriculum development and determines which language skills are useful for the learners in order to accomplish certain professional tasks. ESP instruction is "an approach to language teaching in which all decisions as to content and method are based on the learner's reason for learning" (Hutchinson \& Waters, 1987, p. 19). Thus, conducting a needs analysis is imperative to determine what students need to achieve through the medium of English (Huhta, Vogt, Johnson, Tulkki, \& Hall, 2013).

\section{Oral communication skills in the ESP classroom}

The development of speaking skills has become one of the core elements of ESP training. The need to communicate orally is evident in the light of the cultural challenges of multinational teams working together in increasingly global professional environments. Furthermore, the need for effective communication skills training in English is emphasised by a number of professional bodies, such as the General Medical Council (GMC) or the Association of American Medical Colleges (Kurtz, Silverman, \& Draper, 2005). Consequently, speaking skills should be given due importance in the ESP curriculum.

ESP courses ought to be designed to enable participants to practise speaking for a number of activity types, including

- communicating in typical situations in the workplace or educational context,

- discussing research data,

- giving presentations or talks,

- participating in seminars, lectures, discussions, etc.,

- communicating specialized knowledge to non-professionals,

- communicating in culturally diverse contexts.

In order to help learners communicate more effectively in the workplace, considerable emphasis also needs to be put on the practice of accurate pronunciation of specialist terms. This is particularly important in high-reliability domains, such as medicine or aviation, where accurate and effective communication is critical for safe practice and where miscommunication may result in failure to convey relevant information. Ineffective communication may, in effect, increase the potential for minor errors or even malpractice.

\section{Synchronous and asynchronous communication tools}

In order to help students develop their speaking skills, teachers can use either synchronous or asynchronous communication tools.

Synchronous tools allow teachers and students accessing the same communicator at the same time to engage in real-time communication, irrespective of the distance between them. As a result, participants of a communicative event can im- 
mediately respond to the message they have received. Clandfield (2020) observes that synchronous learning tools such as Blackboard Collaborate enable students to engage in whole-class activities, open and guided pair work, or pair and small group speaking tasks in breakout rooms.

Asynchronous communication does not occur in real time, i.e., participants of a communicative event do not immediately receive and/or respond to messages. One of the most frequently used asynchronous tools is e-mail, which is the "foundation for all forms of online learning and teaching" (Kearsley, 2000, p. 28). Other popular tools include discussion boards or forums, which enable students to interact with the course content, the teacher, and their peers. Some teachers use asynchronous tools to record voice or video messages to which students can respond at a time that is most convenient for them.

Real-time communication has a lot of advantages in all educational contexts. It fosters understanding of the academic content and allows students to put their language knowledge into practice. Moreover, it promotes immediate personal engagement between students and teachers, thus decreasing the sense of isolation (Haythornthwaite \& Kazmer, 2002) that has become common in many educational contexts due to the COVID-19 pandemic. Significantly, synchronous technologies in the ESP classroom may prevent miscommunication or misunderstanding, as they offer varied ways of interacting and enable participants to collaborate and ask questions or offer clarification in real time.

Both synchronous and asynchronous tools can be used as a vehicle for language interaction. The communication type that teachers adopt should reflect the needs of their students. This is particularly true of ESP instruction, which is guided by learner needs.

\section{Developing speaking skills with synchronous tools}

To ensure effective online communication, both teachers and students require access to a teaching platform, a stable Internet connection, a camera, a microphone, and headphones. However, the fact that every student seems to be learning online nowadays can affect the data transfer on the Internet (Wilden, 2020). This may result in low-quality audio, which makes messages in a foreign language difficult to understand and the teaching of pronunciation and intonation challenging.

Apart from the flow rate of the data transfer, the quality of the audio is also dependent on the type of microphone and headphones used. Even though many computers and phones have built-in microphones, Wilden (2020) recommends that online learning participants use headsets, because the microphone is closer to the mouth. Moreover, a headset projects the sound at a more limited, yet more targeted, range. This eliminates the risk of the audio being captured by the speaker's microphone. However, some students are unable to afford good-quality headsets or their built-in microphones may be faulty or broken. In such cases, they usually 
only $\log$ in to a session and passively participate in the lesson, which makes the development of speaking skills in real time almost impossible to achieve.

Not only do messages become easier to understand when the audio quality is satisfactory, but also when each participant has their camera turned on, as body language, gestures and facial expressions reinforce the intended meaning. Nevertheless, both teachers and students might find speaking into a camera intimidating and therefore prefer to only leave their microphones on. Some teachers and students may choose not to switch on their cameras out of fear that others may make judgements concerning their standard of living, accommodation, financial situation, etc. Some learners do not turn on their cameras and/or their microphones because they have competing obligations, e.g., childcare. Moreover, both teachers and students might turn their cameras off due to bandwidth restrictions that can disrupt data transfer and consequently the flow of the lesson. Whatever the reason for switched-off cameras, the fact that both teachers and students do not use them affects the understanding of messages in a foreign language and makes it difficult to reply to what has been said.

Poor Internet access can be a reason why learners are disconnected during an online task in breakout rooms. While monitoring other groups, the teacher might not realize that some students are unable to develop their speaking skills because their partners have unexpectedly left the virtual classroom.

The challenges related to helping learners improve their speaking skills with the help of synchronous communication tools mean that students need to be provided with opportunities to practise those skills with the help of asynchronous communication technologies.

\section{Advantages of asynchronous language communication}

One of the most important advantages of asynchronous communication is the fact that students can complete speaking assignments at a time and location that is most convenient for them. This minimizes interruptions resulting from other obligations, a scenario common in teaching ESP learners, who are often adults either at a tertiary level institution or in a professional work situation. Moreover, the use of asynchronous communication tools improves concentration and the quality of students' utterances (Cullen, 2020). As Hrastinski (2008, p. 52) indicates, "[students] spend more time refining their contributions, which are generally considered more thoughtful compared to synchronous communication".

Kerr (2020) emphasizes that asynchronous speaking tasks are important for shy or reserved students, as they benefit from more independence to complete their activities and often have more opportunities to speak than in synchronous online classes. Learners have more time to think what they want to say and how they want to say it and may also be more motivated than in synchronous settings. They can analyse tasks in detail and listen to recorded material more than once, 
which aids understanding and helps them prepare a more appropriate response. It might also contribute to the quality of the response.

Moreover, responses to asynchronous tasks can be edited to remove background noise, unwanted pauses or fragments. Students' videos can be embellished with filters such as stickers, emojis or colourful text with different fonts, which allows online learners to better express themselves or to create characters that might be more assertive and exuberant than they are in real life. This can lead to greater confidence during speaking assignments and minimises the stress resulting from using a camera. The latter, however, no longer seems to be a significant source of stress, as Kerr (2020) indicates that speaking into a camera or a microphone is becoming normalized, probably due to the fact that the whole educational process has been moved to an online environment. In fact, synchronous speaking activities might be more stressful for students, as they carry the potential of causing embarrassment.

Finally, asynchronous speaking activities are a good introduction to learner autonomy. They help students become responsible for planning, organising, monitoring, and evaluating their learning tasks.

\section{Asynchronous tools for developing ESP speaking skills}

The aim of the following sections is to provide descriptions of three tools that teachers can use to help students develop their oral communication, i.e,. EnglishCentral, Medical English, and Flipgrid. Due to the space limitations, only selected tools available, which are for free and can enhance the development of ESP speaking skills, will be discussed. The authors decided to analyse one tool for developing Business English, one for developing Medical English, and one that could potentially be used for both specialised varieties of English. The analysis was guided by the following questions:

1) Do the tools allow for the asynchronous development of ESP speaking skills?

2) How are they used to develop speaking skills?

3) Do they allow students to improve their speaking skills independently of the teacher?

4) Are they easy to access and easy to use?

5) Do they emphasize the development of accuracy and appropriateness?

6) Are they likely to be appreciated by university students who are digital natives?

\subsection{EnglishCentral (https://www.englishcentral.com/browse/videos)}

EnglishCentral is a website designed to improve listening and speaking skills as well as vocabulary and pronunciation in an asynchronous context. It offers over 15,000 short, interactive videos divided into nine thematic categories (no videos devoted specifically to Medical English are provided) and classified according to three levels of difficulty. Significantly, the short length of the videos is an advan- 
tage, as they maximize students' engagement (Guo, Kim, \& Robin, 2014, as cit. in Brame, 2016, p. 4).

Learners who aim to improve their speaking skills using EnglishCentral first select a video related to their professional and linguistic needs. While watching, they can click on unfamiliar words and pause the video to display the definition of a word. This enables students to learn the vocabulary in context.

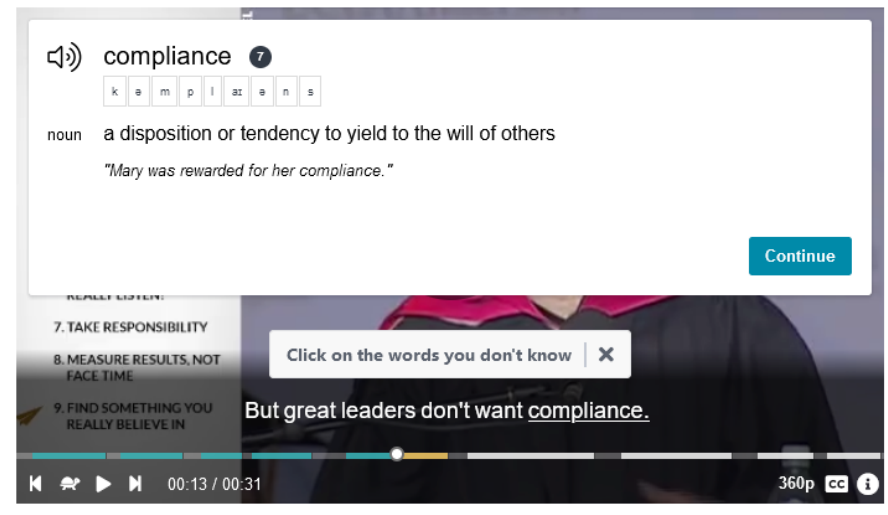

Figure 1: Video from EnglishCentral showing a definition of a word students are not familiar with.

Students can click on the loudspeaker icon to have the options to hear how the word is pronounced, analyse the phonetic transcription, or see how it is used in a sentence. If the pace of the video is too fast, students can click on the turtle icon (see Figure 1 bottom left-hand corner) to slow it down. They can also hear and see selected lines from the video again. The lines contain blanks and the students' task is to fill in the missing letters to recreate the words from the original recording. Automated misspelling detection is provided.

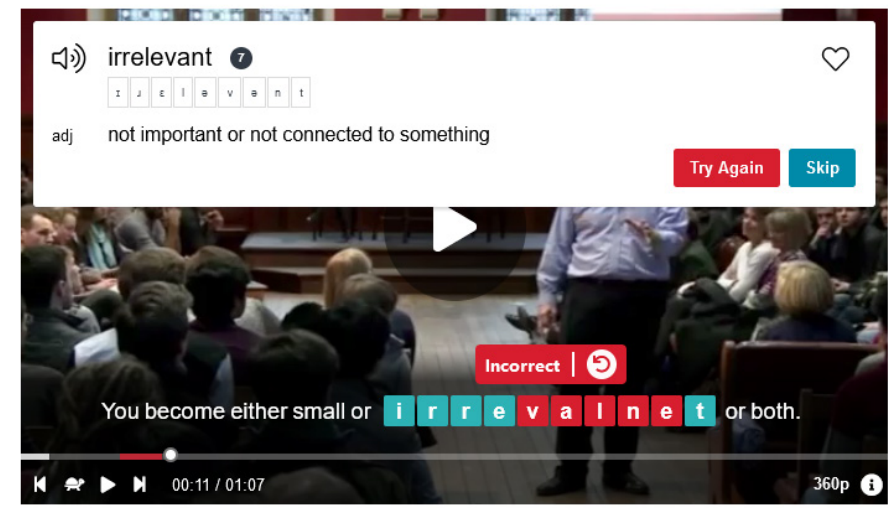

Figure 2: Video from EnglishCentral showing students where they made a spelling mistake. 
The students' subsequent task is to listen to selected lines from the video again and repeat them. They record their voices to practise both pronunciation and intonation and submit the recordings to receive online pronunciation feedback.

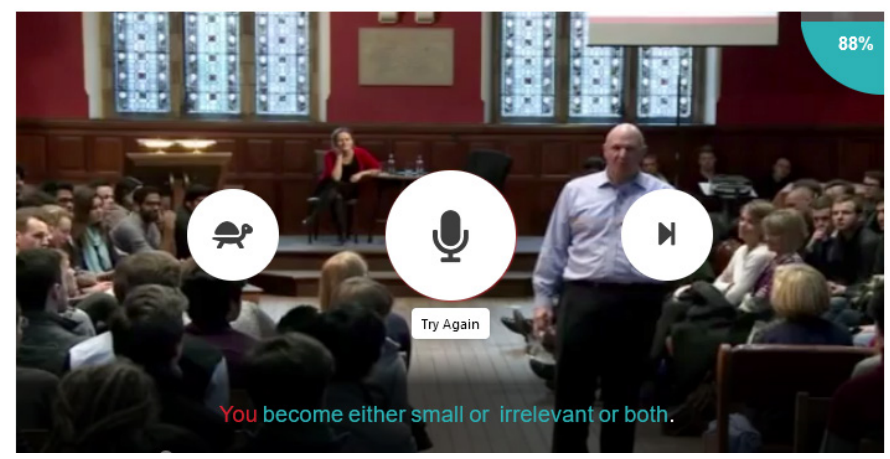

Figure 3: Video from EnglishCentral showing students how to correct their pronunciation and intonation.

Finally, students can chat with a bot called MiMi about the video. The bot displays questions on the screen and students record their voices to answer them (at the time of writing this article this stage was still in the beta version).

EnglishCenteral is relatively intuitive and easy to use. However, it is difficult to find on the Internet and students should therefore be provided with the specific website address.

Following Gajek's (2018, p. 4) suggestion that the selection of tools for developing students' speaking skills should be based on whether they emphasize accuracy and appropriateness since "lack of corrective feedback can produce fluent learners but not accurate enough to be intelligible by most proficient users", EnglishCentral seems adequate as a learning tool. It places emphasis on lexical accuracy, pronunciation and intonation, and is useful for those who need immediate and clear feedback.

Thanks to its interactive videos, EnglishCentral will be appreciated by tertiary students who enjoy online technology. As Lehner (2014, as cit. in Wachtler, Hubmann, Zöhner, \& Ebner, 2016) observes, online users are accustomed to interactions and thus tend to prefer interactive features in videos. Furthermore, an opportunity to interact with an instructional video is likely to enhance learner engagement and lead to improved learning effectiveness (Zhang, Zhou, Briggs, \& Nunamaker, 2006).

Nevertheless, despite the broad range of business topics, EnglishCentral videos are predominantly aimed at in-service learners rather than university students. The latter will probably find themselves practising phrases and roles they are not 
socially familiar with, neither professionally ready for. Consequently, they might not have coping potential when it comes to performing them (Dakowska, 2005).

EnglishCentral is a website for those who appreciate and are able to learn independently of the teacher, as when working with video material students are responsible for their own progress. The question arises whether first-year university students will be able to effectively use the website, as secondary school graduates in the Polish educational context are frequently more familiar with a teacher-driven and teacher-dependent learning process.

\subsection{Medical English https://www.medicalenglish.com/}

Medical English is one of the very few online tools that students of Medical English could use to improve their speaking skills. It is a web-based language course focused on EMP and is divided into 23 core and 30 tech units. While the former section includes more general medical topics, the latter additionally focuses on different areas of professional knowledge and practice, as many units are built around topics related to different medical specialities, e.g., surgery, obstetrics, radiology, and dermatology. Each core unit is subdivided into seven parts, but only one of them is devoted to developing speaking skills. To complete the speaking task in the unit students first need to listen to five sentences containing medical vocabulary introduced in previous activities.

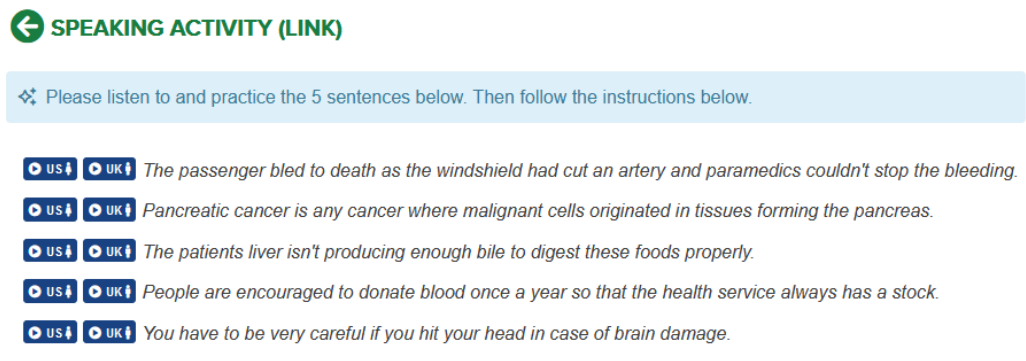

Now it's your turn to perform! Use your computer or smartphone to record the 5 sentences above and paste the link below.
We advise using Youtube $\mathbf{B}$ but users can also paste links to externally hosted files as well. Right now we support MP3
audio and even MP4 video files.

Figure 4: Speaking activity from Medical English (Unit 1 The Human Body)

Students can listen to either American English or British English versions of the sentences, but the British version seems rather artificial. Next, students are asked to speak, record the sentences they repeat and paste the link to the recording in the space provided on the website. Then students' recordings are graded by the teacher.

Medical English allows for the development of the correct pronunciation of medical terms and intonation in sentences containing them. Thus, similarly to 
EnglishCentral, it emphasizes the development of accuracy and appropriateness. However, unlike EnglishCentral, the activities are not interactive, which might discourage tertiary students as interactivity is a factor "attracting and retaining students in online courses and programs" (Moreillon, 2015, p. 41). On the other hand, the lack of interactivity means that it is easy to learn how to work with the activities provided in the course.

Another shortcoming is the fact that no automatic (provided by the tools embedded in the website) and immediate feedback is available, which would instantly enable students to see which areas need improvement. Moreover, to obtain access to all units and activities students should be given a class code, which means that the teacher needs to purchase access to the web resource (which at the moment of writing the article cost more than $\$ 20$ a month).

\subsection{Flipgrid https://flippgrid.com}

Flipgrid is a free video-sharing tool that allows teachers to collect video responses from their students. Once the teachers sign up, they can create grids or learner communities and pose problems to which students reply with 90 -second video recordings. This is an undisputable advantage, as short videos maximize students' engagement in an online learning environment.

To pose a problem, teachers can type in their questions, add a media resource (e.g., YouTube material) or record their own video. The teacher can create a topic they find appropriate or browse more than 30.000 topics created by the Flipgrid community.

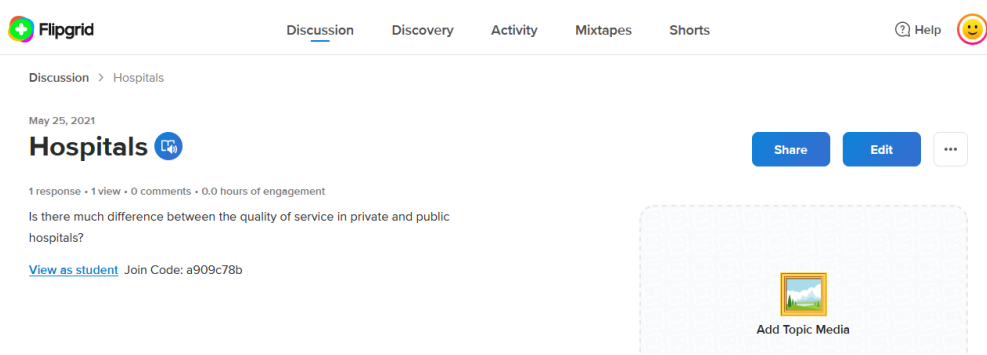

Figure 5: Creating a topic in Flipgrid

Once the teacher has created a topic, they are able to customize it, i.e., select a Video Response Time, allow comments on video response, or enable closed captions in different languages. Moreover, teachers can use the Shorts tool, which allows them to record material and send it to students with a link, which means that students will only be able to watch the video.

To invite students to join the discussion teachers can, among other options, click the 'share topic' button on the topic page or copy the URL and send it to their 
students. Once students have access to the topic, they can start recording and editing their video responses. Students can also record "mic-only" material or cover their image with digital stickers.

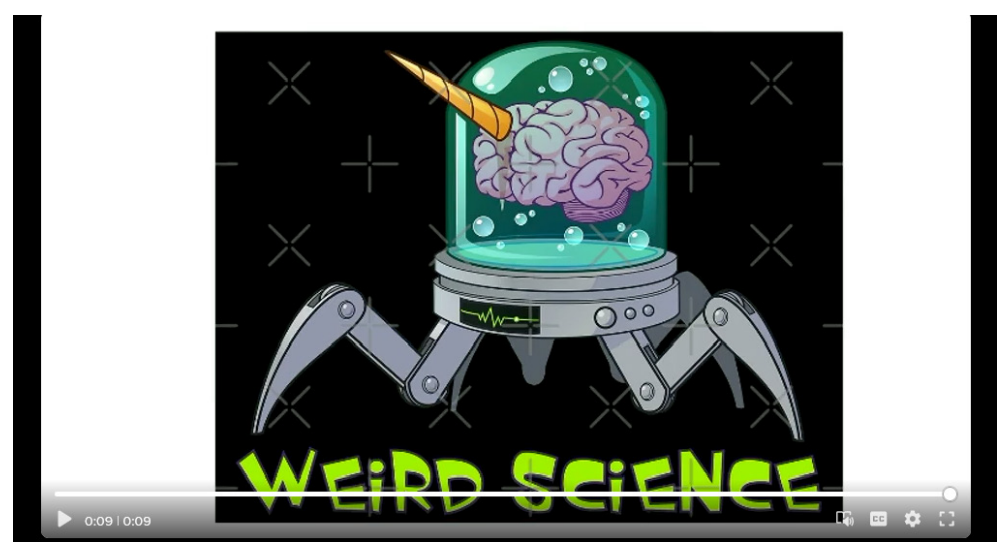

Figure 6: Student response with an avatar.

The teacher can also control the content by setting the Video Moderation mode. As a result, students' videos will only be posted following the teachers' approval.

At first sight, Flipgrid appears difficult to use due to its complicated number of features. However, its diverse interactive features have led to the development of numerous sites and YouTube videos offering dedicated guidance on how to work with it. At present, one in three American teachers uses Flipgrid (Vander Ark, 2019). In fact, Flipgrid is the most interactive of the three tools discussed here, hence it is likely to be more appreciated by tertiary students than EnglishCentral and MedicalEnglish. Moreover, it engages students to reflect on topics that they might feel intimidated to discuss in front of their peers, as thanks to the editing tools provided by Flipgrid they can create personas for themselves, i.e., "fictional, character-driven elements that personify ideal user" (Lowdermilk, 2013, as cit. in Silva Salomão, Rebelo, \& Rodríguez, 2015, p. 6215). According to Davis (2012, p. 1), "persona means mask" behind which students can hide their personal and linguistic insecurities.

Contrary to EnglishCentral and MedicalEnglish, Flipgrid is a video platform that furthers the development of speaking skills at any level and any area of expertise since it is the teacher who creates a grid and decides on how specialised and linguistically advanced a given topic will be. In this respect Flipgrid seems to be the most suitable tool for tertiary students with very little professional experience.

Flipgrid is more suited for teachers who want to enhance students' fluency and creative language use (Vaz Bauler, 2021) rather than linguistic accuracy. It 
does, however, promote metacognition when students watch videos posted by their peers, learn from each other, compare their learning process with that of their friends and self-reflect upon their contributions. As Clark (n.d.) observes, "This allows them to 'think about thinking' and naturally throws them into a state of metacognition". contributions promotes an intellectual exchange of ideas rather than "broadcast" outcomes (Moreillon, 2015, p. 43). According to Rafaeli and Sudweeks (1997), interactivity understood as the process of knowledge construction leads to engagement, sociability, the group's potential to stick together, cooperation, and longevity.

Finally, Flipgrid has a range of accessibility features that allow all learners to participate (Nieves, 2020). For instance, students can use Microsoft's Immersive Reader within both the closed captioning and any text within a topic. The Reader reads any text aloud and breaks words up into syllables for easier decoding.

\section{Conclusions}

Asynchronous communication tools rely on activities that students can access and interact with when it is convenient for them. They relieve the pressure of an immediate response, give learners more control of how and when they want to reply, thus resulting in fewer interruptions, deeper concentration, and better output. Asynchronous technologies also enable participants to create a living document of their learning progress, which can be subject to self-reflection at any time.

Out of the three asynchronous tools discussed in this article Flipgrid seems to be the most suitable for tertiary students who start learning Business or Medical English and who quite frequently have very little or no experience with these areas of expertise, as it allows teachers to create topics that can be specifically tailored for the groups they teach.

Flipgrid also has a bigger and a more varied number of interactive features than EnglishCentral and MedicalEnglish and can thus accommodate more diversified learning styles and personality types.

Even though Flipgrid does not really promote linguistic accuracy, a feature present in both EnglishCentral and MedicalEnglish, it enhances fluency, creative language use and promotes group cooperation and group cohesion. However, the learning process is at least partially teacher-led and does not allow for wholly individual work.

On the other hand, EnglishCentral and MedicalEnglish provide teachers with highly specialised ${ }^{1}$ ready-made topics, which is important when one takes into account the workload of language teachers. Moreover, fluency is important but

1 Flipgrid also contains medical and business topics but they are not as specialized as the ones that are provided by EnglishCentral and MedicalEnglish. 
proficient language users should be able to use a foreign language in an accurate way. EnglishCenral as well as MedicalEnglish enable work on accuracy.

The analysis of the three tools seems to suggest that Flipgrid is the best tool for developing ESP speaking skills at tertiary level. However, websites such as EnglishCentral and MedicalEnglish can be implemented as supporting tools, depending on the requirements of the teaching and learning situation.

Taking into account the fact that education has largely moved online and synchronous communication tools do not always allow for effective development of speaking skills, asynchronous communication tools become a necessity. Nevertheless, teachers should bear in mind that the latter tools complement rather than replace the former ones in developing speaking skills.

\section{References}

Brame, C. J. (2016). Effective educational videos: principles and guidelines for maximizing student learning from video content. CBE-Life Sciences Education, 15(4), es6.

Clanfield, L. (2020). Developing speaking skills remotely. World of Better Learning, 20.10.2020. Retrieved June 15, 2020, from https://www.cambridge.org/elt/blog/2020/10/20/developingspeaking-skills-remotely/.

Clark, H. (2017). 10 Reasons to Catch \#FlipGridFever. Infused Classroom, 28.5.2017. Retrieved June 15, 2020, from https://www.hollyclark.org/2017/05/28/10-reasons-i-have-flipgridfever/.

Courtney, E. (2020). Pros and cons of asynchronous vs. synchronous communication in the remote work environment. Flexijobs. 30.6.2020. Retrieved June 15, 2020, from https://www.flexjobs. com/employer-blog/asynchronous-vs-synchronous-communication-remote-work-teams/.

Cullen, M. (2020). The Pros and Cons of Asynchronous Communication. Instructional Solutions. 10.6.2020. Retrieved June 15, 2020, from https://www.instructionalsolutions.com/blog/asynchronous-communication.

Dakowska, M. (2005). Teaching English as a Foreign Language. A Guide for Professionals. Warszawa: Wydawnictwo Naukowe PWN.

Gajek, E. (2018). Use of technology in teaching speaking skills. In J. I. Liontas (Ed.), The TESOL Encyclopaedia of English Language Teaching (pp. 1-8). New York: John Wiley \& Sons, Inc.

Haythornthwaite, C., \& Kazmer, M. (2002). Bringing the Internet Home: Adult Distance Learners and Their Internet, Home, and Work Worlds. In B. Wellman, \& C. Haythornthwaite (Eds.), The Internet in Everyday Life (pp. 431-463). Oxford: Blackwell Publishing.

Hrastinski, S. (2008). Asynchronous \& synchronous e-learning: A student of asynchronous and synchronous e-learning methods discovered that each supports different purposes. Educause Quarterly, 4, 51-55.

Huhta, M., Vogt, K., Johnson, E., Tulkki, H., \& Hall, D. R. (2013). Needs analysis for language course design: A holistic approach to ESP. Cambridge: Cambridge University Press.

Hutchinson, T., \& Waters, A. (1987). English for Specific Purposes: A Learning-Centred Approach. Cambridge: Cambridge University Press.

Kearsley, G. (2000). Online education Learning and Teaching in Cyberspace. Belmont: Wadsworth Thomson Learning.

Kerr, P. (2020). Making asynchronous speaking practice meaningful. World of Better Learning, 24.6.2020. Retrieved June 15, 2020, from https://www.cambridge.org/elt/blog/2020/06/24/ making-asynchronous-speaking-practice-meaningful/. 
Kurtz, S., Silverman, J., \& Draper, J. (2005). Teaching and learning communication skills in medicine (2nd ed.). Oxford: Radcliffe Publishing.

Moreillon, J. (2015). Increasing interactivity in the online learning environment: using digital tools to support students in socially constructed meaning-making. TechTrends, 59(3), 41-47.

Nieves, K. (2020). 9 new ways to use flipgrid in the classroom. Edutopia, 27.01.2020. Retrieved July 22, 2020, from https://www.edutopia.org/article/9-new-ways-use-flipgrid-classroom.

Orr, T. (2001). English language education for specific purposes. IEEE Transactions on Professional Communication, 44(3), 207-211.

Rafaeli, S., \& Sudweeks, F. (1997). Networked interactivity. Journal of Computer-Mediated Communication, 2(4). DOI: 10.1111/j.1083-6101.1997.tb00201.x.

Silva Salomão, R. C., Rebelo, F., \& Rodríguez, F. G. (2015). Defining „Personas” of university students for the development of a digital educational game to learn Portuguese as a Foreign Language. Procedia Manufacturing, 3, 6214-6222.

Sound issues inside the virtual classroom (n.d.). VEDAMO. Teach your way. Retrieved June 15, 2020, from https://www.vedamo.com/knowledge/platform-tutorials/sound-issues-virtual-classroom-2/.

Vander Ark, T. (2019). Teachers flip over flipgrid. Forbes, 01.7.2019. Retrieved July 22, 2021, from https://www.forbes.com/sites/tomvanderark/2019/07/01/teachers-flip-over-flipgrid/?sh= 7e09b2e7641a.

Vaz Bauler, C. (2021). "Flipgrid netiquette": unearthing language ideologies in the remote learning era. English in Education, 55(3), 251-264.

Wachtler, J., Hubmann, M., Zöher, H., \& Ebner, M. (2016). An analysis of the use and effect of questions in interactive learning-videos, Smart Learning Environments, 3(1), 1-16.

Wilden, S. (2020, March 12). Online Teaching Part 1: Getting Started. [Blog post]. OXFORD UNIVERSITY PRESS English Language Teaching Global Blog, 12.3.2020. Retrieved June 15, 2020, from https://oupeltglobalblog.com/2020/03/12/online-teaching-getting-started/.

Zhang, D., Zhou, L., Briggs, R. O., \& Nunamaker, J. F. (2006). Instructional video in e-learning: Assessing the impact of interactive video on learning effectiveness. Information \& Management, 43(1), 15-27. 